Muse, but is not planned, at present, on quite such a large scale. Nevertheless a core store of more than 8,000 words with an access time of $2 \mu \mathrm{sec}$. is to be provided, and there is provision for at least four magnetic tape mechanisms to be attached to the machine. Two very interesting features are the proposed structure of the arithmetic unit and a new method of number representation it is intended to incorporate. 'The arithmetic unit is to be built on the same principle as that of the Maniac at Los Alamos, using asynchronous circuitry, but will include many additional cross-connexions between registers to facilitate rapid arithmetical working. A number representation, called 'significant digit' representation, will be used. This is a form of floating point representation which avoids the appearance of many meaningless digits at the end of approximate numbers, while retaining a few guarding digits against rounding errors.

An important application of fast machines is to problems in supersonic flow-past aerofoils and other surfaces. An interesting contribution to this subject was made by Mr. D. S. Butler of the Armaments Research and Development Establishment, who described some recent work he has carried out on this problem.

In order to calculate the lines of flow around and pressures on a solid figure in a supersonic airstream it is necessary to solve a hyperbolic partial differential equation in three variables. $H_{\theta}$ discussed various methods of doing this and made particular reference to the method of characteristics, a powerful technique for solving equations of this type. $\mathrm{He}$ went on to describe a particular example of stationary flow around a body shaped like a delta-wing aircraft and showed how the calculations had been carried out in this case using the computer at Fort Halstead, a Ferranti Mk. I*.

Other topies at the conference which excited considerable interest concerned the control of production in factories and the application of operational research techniques to this and allied problems. Mr. F. Bryen of Imperial Chemical Industries described an application of punched card machinery to factory con. trol, and Mr. J. Harling of Urwick, Orr and Partners deait very interestingly with the use of computers for operations research. An application of one of the latter techniques within the Shell group of companies formed the subject of a later address by Mr. C. S. Galer. There were also sessions on keeping accounts by computer, on auditing the accounts so kept. on the training and selection of programmers, on automatic programming, and on working experience with magnetic tape mechanisms. On the mathematical side, Dr. A. S. Householder of the Oak Ridge National Laboratory, Tennessee, directed attention to some of the pitfalls in the techniques commonly used on computers. In particular, he considered the stability of two methods of inverting a matrix, and concluded that the method of rotation is not more stable than the method of elimination, although an argument can be adduced to the effect that it is. After this paper, as after all the formal papers presented, there was a lively discussion, in which many of the delegates took part.

A wide-ranging review of the state of the computing art was given by two speakers, Mr. J. A. Goldsmith of Robson, Morrow and Co., and Dr. A. S. Douglas of the University of Leeds. Mr. Goldsmith noted that delivery of 76 installations of electronic computers had so far been made in the United Kingdom and that 33 were on order, although recently the tempo of orders had slackened. Much of the work in the commercial field had so far been unambitious and the results somewhat disappointing. He felt that it would be 5-10 years before computers played a full part in helping management to control their organizations. Dr. Douglas reviewed the work of computers in British universities. Much work has been done in training in their use at the postgraduate-level, and he felt that this could well be extended to the undergraduate-level. $\mathrm{H}_{\theta}$ discussed the problem confronting universities in the installation and use of large-scale, machinery, and suggested that it would be desirable for three or more of the large fast computers such as Muse to be installed in universities, where they would act (on a service basis) as focuses for local computer users. Ho gave details of serviceability and use of typical present-day university installations, and concluded that a high standard of efficiency can be attained.

All the sessions were very well attended throughout. It is intended in the future to hold annual conferences of the Society at various centres in the United Kingdom, the next conference being planned for June or July 1960.

A. S. Douglas

\title{
THE INTERNATIONAL INSTITUTE OF REFRIGERATION
}

$\mathrm{T}$ HE first International Congress of Refrigeration was held in Peris in October 1908. Shortly after this, in January 1909, the International Association of Refrigeration was established, following the suggestion of Kamerlingh Onnes, the name being changed to the International Institute of Refrigeration just after the First World War. The organization has therefore just celebrated its jubilee.

The general objective of the Institute is the development of the science and techniques of refrigeration in the international field. It promotes scientific research, as well as the teaching and popularization of refrigeration and its application in all fields, particularly in food preservation, health and industrial processes. The International Institute of Refrigeration headquarters are in Paris.
The main tasks of the Institute are determined by the general conference, at present presided over by Dr. Ezer Griffiths. This meets every four years, at the same time as an International Congress of Refrigeration, also organized by the Institute. Executive power is vested in an executive committee. A technical board, of which Dr. J. C. Fidler is the current president, co-ordinates the scientific and technical activity of nine commissions, which between them cover all aspects of refrigeration matters from fundamental research to applications in agriculture, transport, etc.

The tenth International Congress of Refrigeration was held in Copenhagen during August 19-26 and was attended by about 1,500 delegates from all over the world. About 300 scientific and technical 
papers were discussed at plenary sessions and at meetings of all the commissions held during the period of the Conference.

The Institute publishes six times a year a Bulletin which appears in both English and French, the two official languages of the Institute. The Bulletin contains abstracts of scientific and technical articles and information about current research in refrigeration and on other refrigeration activities from all over the world. The Institute also publishes the works of its various commissions.

Full membership of the Institute is restricted to the governments of member countries, which at present number 35, including the United Kingdom, the United States and the U.S.S.R. The United Kingdom interests in the Institute are co-ordinated by the Department of Scientific and Industrial Research, with the advice of a Standing Committee representing research, institutional and industrial interests in Great Britain.

In 1952, the Institute introduced associate membership, available to qualified firms, institutions or individuals active in the science or in the industry of refrigeration. The annual subscription is about $£ 13$ for firms and institutions and $£ 310 s$. for individuals. Associate members receive the Bulletin and the proceedings of the nine international com. missions of the Institute, together with the texts of reports presented. Associate members may participate in the work and the meetings of the commissions in which they are interested, and can also use the services of the large library of the Institute. Applications for associate membership may be made to the Director of the International Institute of Refrigeration, 177 boulevard Malesherbes, Paris $\left(17^{\circ}\right)$.

\section{STERIC ASPECTS OF THE CHEMISTRY AND BIOCHEMISTRY OF NATURAL PRODUCTS}

$\mathrm{T}$ HE interest taken in stereochemical problems by chemists and biochemists alike has been greatly increased in recent years, and the Biochemical Society recognized this fact by arranging a symposium on "Steric Aspects of the Chemistry and Biochemistry of Natural Products", which was held in the Senate House of the University of London on June 30. The chairman of the morning session, Prof. A. Neuberger (London), discussed some of the main trends of recent work in this field and emphasized the importance of stereochemistry in modern enzymology.

Dr. W. Klyne (London) then discussed in a comprehensive manner the types of evidence used for establishing relative or absolute configurations of asymmetric compounds. The term 'absolute configuration' can now be used with confidence, as Bijvoet and his colleagues working in Utrecht have demonstrated by means of a special X-ray technique that the Fischer convention for glyceraldehyde happens to be correct. Dr. Klyne pointed out that the most satisfactory method of correlating two asymmetric compounds is by a chemical reaction which does not involve the asymmetric centre. The second type of approach is concerned with chemical reactions in which one or more of the linkages of the asymmetric atoms are broken. The stereochemical correlation in this situation must be based on kinetic and other evidence and must involve certain assumptions about the mechanisms of the substitution concerned.

Dr. Klyne then went on to discuss the deductions which can be made from studies of asymmetric synthesis, methods used successfully by Prelog and by Cram. Another type of approach which was developed mainly by Fredga in Sweden, and which is probably not sufficiently widely known, is based on the study of melting points of mixtures of a compound of known configuration and a structurally similar compound of unknown configuration. If the two compounds have opposite configurations they may form in the solid phase a quasi-racemic compound, and this can be deduced from the melting-point curve.

Reference was also made to the information obtained from the applications of X-ray analysis, especially to compounds with more than one asymmetric centre. Finally methods were discussed which depend on a numerical comparison of the values of optical rotations of structurally related compounds. These calculations and deductions have in the past been largely based on measurements at a single wave-length and have indeed yielded much valuable information. In recent years this tool has been made more powerful by extending the measurements to the whole visible and a large part of the ultra-violet range of the spectrum. In this development (rotatory dispersion), Djerassi of Detroit has taken the leading part.

Steric aspects of the biosynthesis of terpenes and steroids were considered by Dr. D. Arigoni (Zurich), who discussed first the formation of an isopentane derivative from acetate. The early stages of the synthesis consist of a condensation of acetoacetyl-CoA with acetyl-CoA to give the CoA derivative of $\beta$-hydroxy- $\beta$-methylglutaric acid. The latter is then reduced, probably through the aldehydo acid, to $\beta, \delta$-dihydroxy- $\beta$-methylvaleric acid or movalonic acid. The absolute configuration of this compound has been unambiguously related recently by Eberle and Arigoni to that of quinic acid, which in turn had been established by Dangschat and Fischer in 1950 by relating it to glyceraldehyde. Dr. Arigoni then referred to the stereochemical problems involved in the conversion of leucine to $\beta$-hydroxy- $\beta$-methylglutaconic acid, which occurs through the CoA esters of $\beta$-mothylcrotonic acid and $\beta$-methylglutaconic acid. The hydration of the double bond and the carboxyla. tion of methylcrotonic acid must be stereospecific and this is also likely to apply to the reduction of mevaldic acid to mevalonic acid. The next steps in the reaction sequence are the simultaneous decarboxylation and elimination of the tertiary hydroxyl group from the pyrophosphate of mevalonic acid to give isopentenyl pyrophosphate and the isomerization of the latter to give dimethylallyl pyrophosphate; it can be postulated that the isomerization is stereospecific and Dr. Arigoni thought it probable that only one of the two hydrogen atoms of iso. pentenyl pyrophosphate is involved in the isomerization. 